\title{
Diatom flotation at the onset of the spring phytoplankton bloom: an in situ experiment
}

\author{
José Luis Acuña ${ }^{1, *}$, Márcos López-Alvarez ${ }^{1}$, Enrique Nogueira ${ }^{2}$, \\ Fernando González-Taboada ${ }^{1}$ \\ ${ }^{1}$ Departamento de Biología de Organismos y Sistemas, Universidad de Oviedo, Oviedo 33071, Spain \\ ${ }^{2}$ Centro Oceanográfico de Gijón, Instituto Español de Oceanografía, Gijón 33212, Spain
}

\begin{abstract}
We used a new type of sediment trap to conduct an in situ test on the buoyancy properties of diatoms before and during the growth phase of the spring phytoplankton bloom (SPB). Diatoms shifted from a sinking pattern before the bloom, while their populations were not growing, to a neutrally buoyant pattern during bloom development, when calm conditions prevailed, light was abundant and phytoplankton were actively growing. This shift was mainly due to the upward motion of centric diatoms during the growth phase. Our field experiment confirms laboratory experiments and field observations showing that diatoms, the paradigm of sinking phytoplankton, approach neutral buoyancy when conditions are adequate for growth, a fact that is not taken into account in most SPB and phytoplankton dynamics models.
\end{abstract}

KEY WORDS: Diatom $\cdot$ Spring bloom $\cdot$ Buoyancy

\section{INTRODUCTION}

To persist, phytoplankton species must remain in the upper layers of oceans and lakes, where light is available for photosynthesis. Consequently, any tendency to sink should be negatively selected; otherwise phytoplankton populations would be quickly drained to the non-illuminated portion of the water column, becoming extinct (Hutchinson 1967). In a theoretical paper, Huisman et al. (2002, p 1) contend that most phytoplankton are denser than water and tend to sink, which poses a puzzling paradox: 'How do sinking phytoplankton species manage to persist?' These authors propose an elegant solution based on early work by Riley et al. (1949), who showed that persistence of sinking phytoplankton is possible when moderate levels of turbulence keep these cells in the upper part of the water column. Progressively refined versions of Riley's influential theory have appeared during the last 5 decades, and have shaped our understanding of phytoplankton ecology (e.g. Shigesada \& Okubo 1981, Huisman et al. 1999, 2002).

The purpose of the present study is to show that the notion of sinking phytoplankton does not bear up to close scrutiny by an in situ experiment during a critical period in the production cycle. Two of the 3 main types of marine phytoplankton, the microflagellates and the dinoflagellates, are motile and consequently cannot be classified among the sinking phytoplankton. This leaves the diatoms, which are considered by many to be the paradigm of sinking phytoplankton. Their cells are encapsulated within heavy silica frustules and tend to sink when not growing actively, which is often the case during laboratory experiments where the physiological or environmental conditions are not properly controlled. However, they have succeeded at colonizing the ocean on the basis of transient periods of explosive growth which sustain the world's fisheries (Falkowski et al. 1998) and which account for one quarter of the ocean's primary production (Raven \& Waite 2004). Clearly, the buoyancy properties of diatoms during these growth periods, or blooms, must be of crucial adaptive value, as is implicitly acknowledged by the inclusion of fixed, sinking loss terms in bloom models (e.g. in the critical depth model, Platt et al. 1991; in the critical turbulence model, Huisman et al. 1999; in the phytoconvection model, D'Asaro 2008). But do diatoms really sink during blooms? 
Five decades of laboratory experimentation have confirmed that diatoms can achieve neutral or positive buoyancy, most likely by rapidly altering the ion content of their vacuolar sap (e.g. Smayda 1970, Anderson \& Sweeney 1977, Smetacek 1985, Raven \& Waite 2004, Woods \& Villareal 2008). This mechanism may include the biosynthesis of organic cations (e.g. variously methylated ammonium ions, Boyd \& Gradmann 2002). Furthermore, there is also evidence of strong positive buoyancy in diatom auxospores right after sexual reproduction (Waite \& Harrison 1992). Neutral or positive buoyancy happens when growth is not limited by nutrients or light (Anderson \& Sweeney 1977, Waite et al. 1992a), which applies during bloom conditions. In the field, visual observations of extensive vertical migration by diatom mats have been conducted by SCUBA divers or using video recorders in the oligotrophic North Pacific Gyre (Villareal et al. 1993, 1999). This environment is not representative of bloom conditions, but it is clear that these diatoms regulate their buoyancy and cannot be classified among the sinking phytoplankton. During the Southern Ocean Iron Release Experiment (SOIREE), a diatom bloom was experimentally stimulated by addition of iron to seawater. By carrying water samples to the onboard laboratory and observing sinking rates in settling columns, Waite \& Nodder (2001) were able to monitor changes in the buoyancy properties of diatoms during the bloom. Additionally, during the spring phytoplankton bloom (SPB) in an enclosed fjord, Lännergren (1979, p. 1) observed that diatom 'sinking appeared negligible from the onset of the bloom to its culmination'. Thus laboratory experiments and a series of striking field observations support the existence of buoyancy shifts in diatoms during blooms, although these physiological subtleties have not been incorporated into bloom and population dynamics models, where diatoms are assumed to sink at fixed velocities (e.g. Platt et al. 1991, Huisman et al. 1999, 2002, Huisman \& Sommeijer 2002, D'Asaro 2008). As a way out of this impasse, the logics of the scientific method call for an inferential field test of the fixed sinking assumption during the onset of a bloom; that is, right at the critical initiation conditions that these models are trying to predict.

The SPB represents an excellent target for an experiment. Due to its gigantic proportions, the SPB can be readily detected from space (Siegel et al. 2002) and has profound implications for the biogeochemistry and productivity of temperate oceans (Falkowski et al. 1998). Moreover, research on the causes of the SPB lies at the foundations of biological oceanography (Miller 2004). Lastly, the timing of the SPB is to some extent predictable from published statistics (Siegel et al. 2002), so that an oceanographic research cruise can be arranged to chase after the bloom and conduct an experiment. Nevertheless, direct observation of diatom cell buoyancy in the open ocean in temperate and polar latitudes is difficult during the SPB because of the small size of unaggregated, bloom-forming diatoms, the intense turbulence that characterizes winter and spring seasons in those seas, the transient nature of this phenomenon and the logistic constraints typical of offshore work. Sediment traps represent a practical alternative. They consist of conical or cylindrical structures that are stationed vertically with an open end facing upwards, so that they collect sinking particles during a specified period of time. We have modified the design of classical sediment traps to conduct a qualitative buoyancy test free of the confounding effect of turbulence. Our results confirm that diatoms adjust their buoyancy during the SPB in the open ocean and suggest that fixed sinking rates cannot be assumed to model the onset of SPB.

\section{MATERIALS AND METHODS}

Trap design. The trap incorporated 4 upward-facing tubes (U tubes), identical to those of classical sediment traps, to collect sinking particles (Fig. 1). An additional set of 4 control tubes ( $\mathrm{C}$ tubes) were closed at the beginning of the deployment to register ambient phytoplankton concentrations (Fig. 1). Finally, 4 downward-facing tubes (D tubes) collected positively buoyant particles (Fig. 1). Because turbulence is isotropic, it should affect particle capture by $U$ and D tubes equally. This design allows testing the null hypothesis that turbulence is the only factor involved in particle exchange between the collection tubes and the environment, which should cause a symmetric accumulation pattern $(u=d$, where $u$ and $d$ are average particle concentrations in $U$ and $D$ tubes, respectively). Any significant deviation from symmetry between the $U$ and D tubes must be due to either positive $(u<d)$ or negative $(u>d)$ buoyancy.

Experiment logistics. The buoyancy trap experiment was conducted during the DINAPROFIT II cruise in the Bay of Biscay between 23 February and 19 March 2005 (Fig. 2A). This time window maximized the chances of observing the SPB at this latitude, according to published timing statistics (Siegel et al. 2002). We deployed the drifting sediment trap on 8,11, 14 and 17 March at 11:50, 10:57, 07:52 and 08:06 h, for 28.0, 23.0, 24.2 and $24.3 \mathrm{~h}$, respectively.

Oceanographic conditions. Moderate resolution imaging spectroradiometer (MODIS) Aqua L2 images of surface chlorophyll a ( $\mathrm{chl}$ a) concentration during each trap deployment were retrieved at nominal resolution (Feldman \& McClain 2008; Fig. 2A). Due to severe weather conditions, the ship had to take shelter 

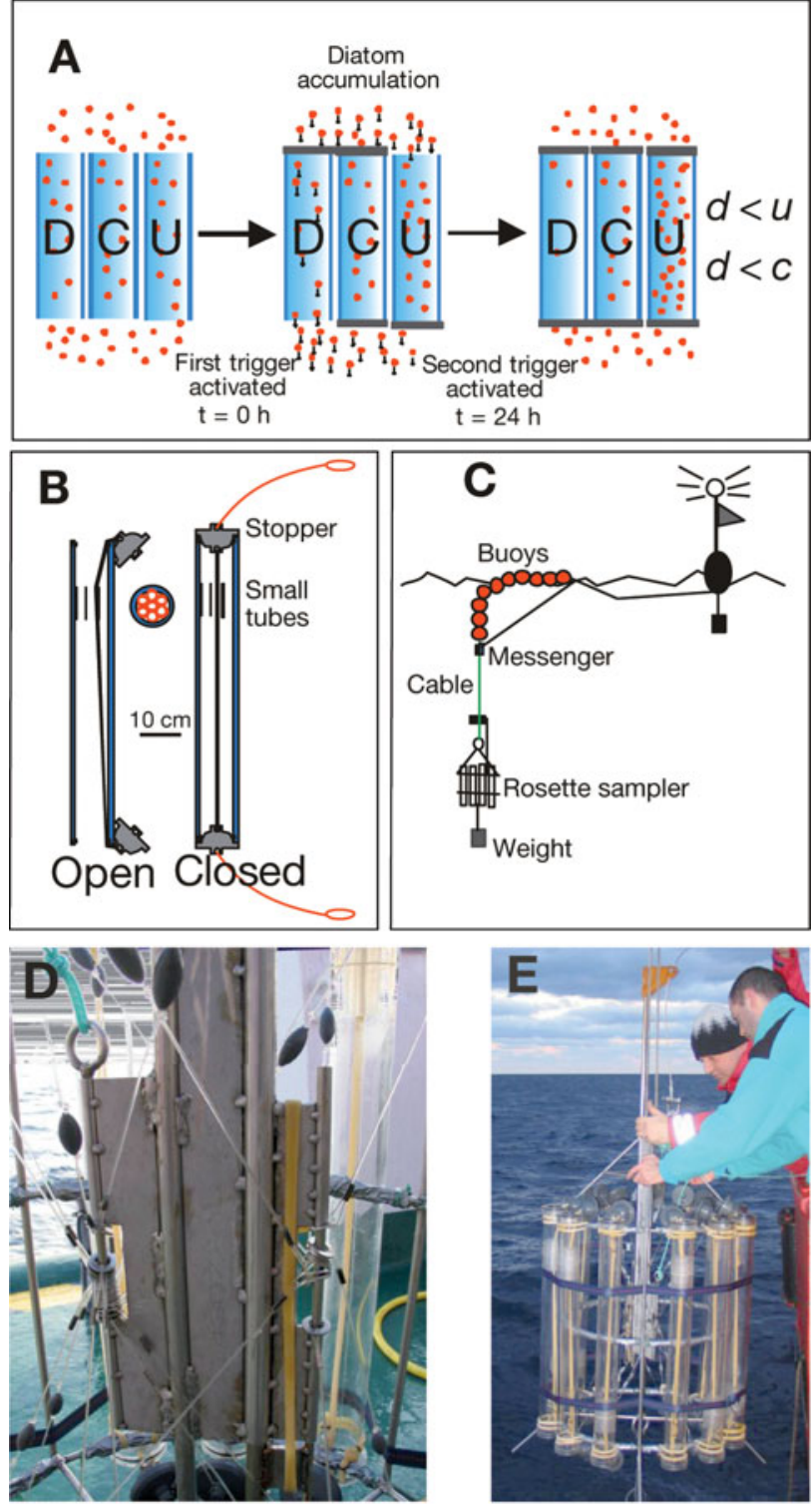

Fig. 1. (A) Buoyancy trap concept. Trap functioning is illustrated for an assemblage of sinking diatoms (red dots). Upward-facing (U), downward-facing (D) and control (C) tubes are indicated by the blue cylinders; lids are in grey. $d, c, u$ are the average particle concentrations within the $\mathrm{D}, \mathrm{C}$, and $\mathrm{U}$ tubes, respectively: inequalities are predicted results for the null hypothesis of sinking diatoms. (B) Schematic diagram of a sampling tube fully open (left) and fully closed (right). (C) Schematic diagram of the deployment system. (D) Triggering mechanism detail: the first trigger (left) is activated by pulling a rope, while the second trigger (right) is activated by releasing a messenger. (E) Trap deployment

several times during the cruise. For this reason, we have used wind and wave data from the seawatch moored buoy Cabo Peñas $\left(43^{\circ} 43.8^{\prime} \mathrm{N}, 6^{\circ} 10.2^{\prime} \mathrm{W}\right.$, Fig. 2A), located $50 \mathrm{~km}$ west of our sampling area (Fig. 2A). Buoy wind data were highly correlated with data from the onboard Aanderaa meteorological sta- tion (calibration done with offshore wind data only, $\mathrm{r}^{2}=$ 0.701, p < 0.001). Daily integrated photosynthetically active radiation (PAR) was calculated from solar radiation, given that ca. $42.5 \%$ is in the $400-700 \mathrm{~nm}$ band (Jitts et al. 1976). Trap deployments were done at a $1920 \mathrm{~m}$ deep station located at $44^{\circ} 4^{\prime} \mathrm{N}, 5^{\circ} 28^{\prime} \mathrm{W}$, at a distance of $47 \mathrm{~km}$ from the coast, and representative of an open ocean environment (Fig. 2A). Fluorescence profiles were registered using a SBE 21 Sealogger CTD. Fluorescence readings were calibrated against measurements of chl a concentration $\left(\mathrm{r}^{2}=0.510, \mathrm{p}<\right.$ $0.001, \mathrm{n}=302$ ) done on acetone extracts following standard methods (Yentsch \& Menzel 1963). For this, $100 \mathrm{ml}$ water samples were taken at discrete depths $(0$, $20,40,80 \mathrm{~m}$ and bottom of the convective layer) using Niskin bottles.

Trap deployment. The function of the trap is illustrated in Fig. 1A, assuming an assemblage of diatoms that sink. All three tube types were fully open when deployed at $20 \mathrm{~m}$, thus they became equally filled with the particle suspension at that depth. A first trigger was released by pulling a rope (Fig. 1D) to close the upper opening of the D tubes, both openings in the $C$ tubes, and the lower opening in the U tubes, initiating the experiment $\left(t=0 h_{i}\right.$ Fig. 1A). The trap was allowed to drift for $24 \mathrm{~h}$, during which time the $\mathrm{D}$ and $\mathrm{U}$ tubes lost and gained diatoms respectively, while the diatom concentration in the $\mathrm{C}$ tubes remained unaltered (Fig. 1A). At $\mathrm{t}=24 \mathrm{~h}$ and while the trap was still at $20 \mathrm{~m}$ depth, a metal messenger which was attached to the buoys (Fig. 1C) was allowed to slide along the cable, and to impact on a second trigger (Fig. 1D) which closed all the lids (Fig. 1A). The trap was then brought to the surface for sample collection and analysis.

Each sampler consisted of a methacrylate cylinder $75 \mathrm{~cm}$ long and $7 \mathrm{~cm}$ in diameter built according to VERTEX specifications (Knauer et al. 1979; Fig. 1B). The collecting end was fitted with a set of smaller tubes to keep any turbulence from propagating inside the cylinder. Each cylinder was mounted vertically in a rosettelike sampler, and was equipped at both ends with PVC stoppers joined by an elastic rubber tubing inside the methacrylate cylinder, like the closing system of a regular Niskin bottle. For deployment, these cylinders were kept open at both ends by a nylon string attached to 1 of 2 triggering mechanisms in the rosette sampler.

The deployment system hung from a steel cable attached to a string of floats to dampen wave movements (Fig. 1C). The number of buoys was calibrated so the rosette sampler would stay at $20 \mathrm{~m}$ depth; the sampler was kept vertical by the pull of a weight.

Sample analysis. After retrieval, the trap was covered to avoid exposure to intense light. Each tube was individually brought to the laboratory and thoroughly mixed to homogenize contents. Samples for the analysis 
A

Non-growth phase

Growth phase
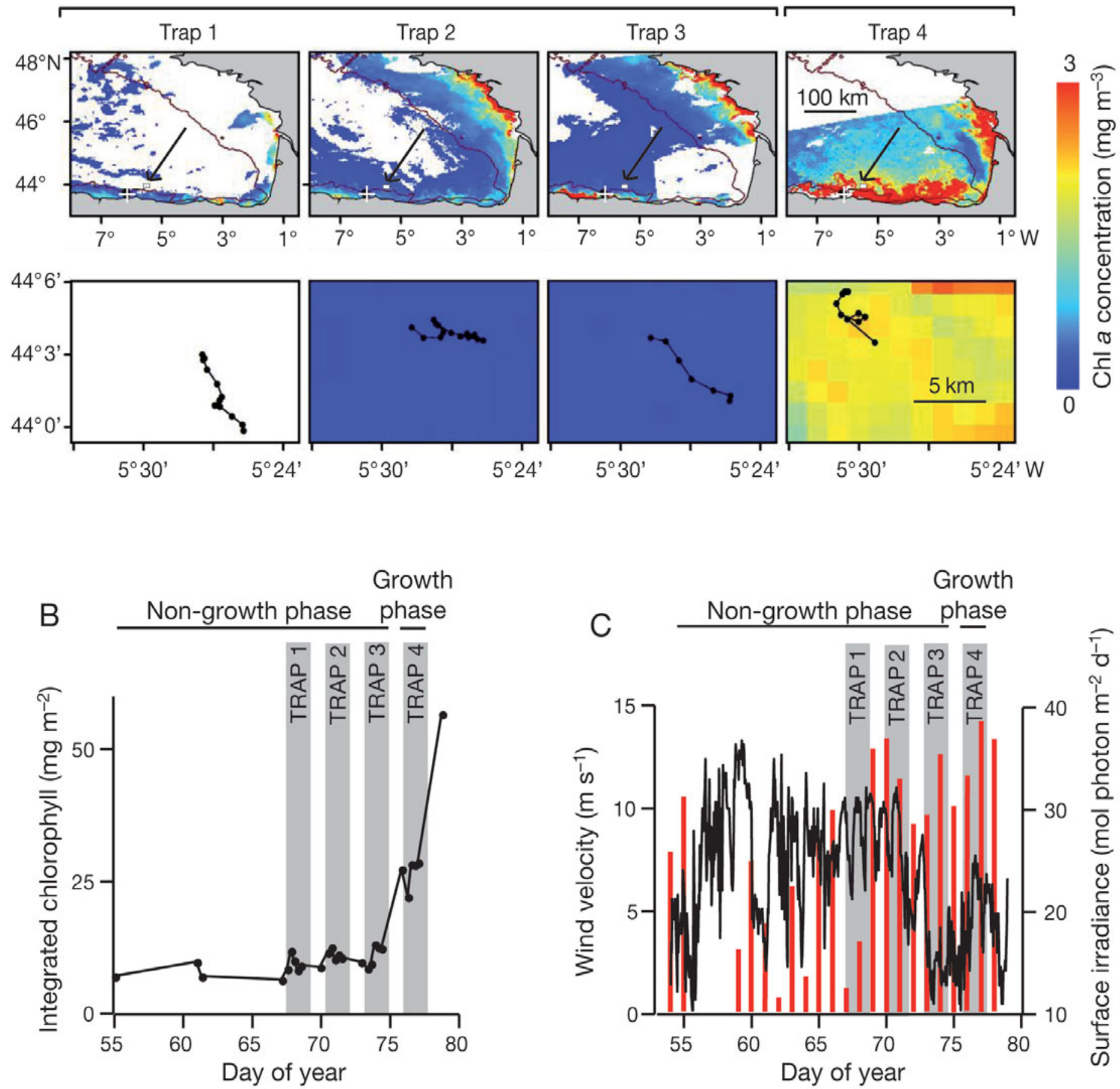

Fig. 2. Study site and oceanographic conditions. (A) Surface chlorophyll a (chl a) concentration composites, derived from satellite sensors, for the Bay of Biscay (upper row) and the deployment site (lower row) during the onset of the 2005 spring phytoplankton bloom. White indicates that no data were available due to cloud cover. The contours indicate the $200 \mathrm{~m}$ isobath, which marks the continental slope in this area. The crosses indicate the position of the buoy where measurements of wind speed were conducted. The arrow points to a small square which is the study area. This area is expanded to show detail in the lower row of panels. Lines and dots in these panels indicate the trajectory of the sediment traps during deployment. Data from 2 swaths belonging to the same day were merged to obtain the composite image for trap 4. (B) Time course of integrated ( 0 to $40 \mathrm{~m}$ depth) chl a. Each dot represents a single observation (i.e. one CTD cast). Several measurements of ambient chl a were conducted during each trap deployment. Shaded areas indicate each of the trap deployments conducted. (C) Time course of wind speed (black line) and daily integrated photosyntetically active radiation (red bars) 
of phytoplankton biomass $(100 \mathrm{ml})$ were preserved and analysed following the Utermöhl technique. Biomass of each diatom species was estimated using conversions from cell volume to cell carbon (Hillebrand et al. 1999, Menden-Deuer \& Lessard 2000). These equations may overestimate the actual carbon content of the largest cells due to the vacuole (Menden-Deuer \& Lessard 2000). However, this would only lead to spurious results in our experiment if there were differences in the size of ascending or descending diatoms, which was not the case (data not shown).

Data treatment and statistical analysis. Our buoyancy trap experiment had a 2-way, mixed effects ANOVA design, with a random factor (Trap) with 4 levels corresponding to each of the trap deployments (Traps 1 to 4), and a fixed factor (Tube) with 3 levels corresponding to each of the tube treatments (U: upwards-facing; D: downwards-facing; C: control). The dependent variable is the diatom concentration inside the tubes (either total diatoms, centric diatoms or pennate diatoms). Our null hypothesis was that diatoms sink at a fixed velocity, thus $d<u$ and $d<c$ was expected across all 4 traps (Fig. 1A); this was investigated by testing the D vs. U and D vs. C main effects. Planned tests of the Trap $\times(\mathrm{D}$ vs. U) and Trap $\times(\mathrm{D}$ vs. C) interaction (Underwood 1997) were used to investigate buoyancy shifts. We also conducted planned, $\mathrm{D}$ vs. U and D vs. C tests within each trap following McKone (1993), although these tests have less power. A similar analysis carried out on number of cells rather than biomass did not render such clear-cut results, because there was a numerical dominance of small diatoms that did not show any buoyancy response.

To compare the magnitude of the D vs. U asymmetry across diatom species, independent of their concentration in the environment, we defined a biomass-normalized asymmetry (BNA, $\mathrm{m} \mathrm{d}^{-1}$ ):

$$
\mathrm{BNA}=\frac{u-d}{c} \frac{v}{s t}
$$

where $u, d$ and $c$ are the average particle concentrations in the $\mathrm{U}, \mathrm{D}$ and $\mathrm{C}$ tubes, respectively $\left(\mu \mathrm{g} \mathrm{C} \mathrm{m}^{-3}\right)$, $v$ is the volume of the collector $\left(2.07 \times 10^{-3} \mathrm{~m}^{3}\right), t$ is the time of deployment of the trap (days; it varied between traps) and $s$ is the collection surface $\left(28.3 \mathrm{~cm}^{2}\right)$. Here $C$ is assumed to represent the ambient concentration. The constant v/st was added for dimensional consistency with a velocity, and to correct for deployment duration. Not all species were present in all traps, or in all 12 tubes within a trap. For calculation of BNA, we used only those species with densities above the detection level in at least 9 out of 12 collectors in a trap. During the experiment, densities below the detection level generally corresponded to control collectors, which remained closed during deployment.

\section{RESULTS AND DISCUSSION}

The 2005 winter was extremely cold and dry, leading to record mixed layer depths reaching down to $400 \mathrm{~m}$ (Somavilla et al. 2009; note the clear inflection of the temperature and density profiles at the base of the mixed layer in Fig. 3). During the first 3 trap deployments, phytoplankton were not growing actively, as depicted by a low and constant biomass at the study site ( $10 \mathrm{mg} \mathrm{chl} \mathrm{a} \mathrm{m}^{-2}$; Fig. $\left.2 \mathrm{~B}\right)$ and at the Bay of Biscay at large (Fig. 2A). Nevertheless, slightly higher fluorescence levels were apparent at the upper mixed layer (Fig. 3), which suggests that a phytoplankton inoculum was being sustained by a deep convection mechanism (Backhaus et al. 2003, D'Asaro 2008). The fourth trap was deployed during active phytoplankton growth,

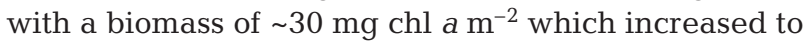
$\sim 60 \mathrm{mg} \mathrm{chl} \mathrm{a} \mathrm{m}^{-2}$ by the end of the cruise (Fig. 2B). This increase was also evident in the Bay of Biscay (Fig. 2A), and followed a marked decrease in wind velocity and an increase in irradiance (Fig. 2C) which probably caused the development of a slight, $0.4^{\circ} \mathrm{C}$ surface temperature gradient (Fig. 3). Thus the bloom developed either through a critical depth mechanism (Sverdrup 1953) caused by an incipient stratification or by an alternative mechanism based on the decay of ocean turbulence (Sverdrup 1953, Townsend et al. 1992, Ellertsen 1993, Huisman et al. 1999). Onset of the SPB was associated with a transition from flat vertical fluorescence profiles during the non-growth phase to a surface, $50 \mathrm{~m}$ thick high-chlorophyll layer during the growth phase, with little evidence of thin layers or subsurface maxima (Fig. 3). Our trap experiment took place at $20 \mathrm{~m}$ depth, almost exactly at the middle of the upper high-chlorophyll layer (Fig. 3).

Diatoms shifted from a sinking pattern $(d<u)$ during the non-growth phase prior to the SPB to a neutrally buoyant pattern $(d=u)$ during the growth phase (Fig. 4). This shift was confirmed by a significant Trap $\times(\mathrm{D}$ vs. U) interaction (Table 1$)$ and a sudden drop between Traps 1 to 3 and Trap 4 in the significance of the planned, within-trap D vs. U comparisons (Fig. 4; Table 2). This was mainly due to a change in the buoyancy properties of centrics, the oldest group among the diatoms ( 250 million years ago; Raven \& Waite 2004). The centrics shifted from sinking $(d<u)$ during the non-growth phase to positive buoyancy $(d>u)$ during the growth phase (significant Trap $\times$ [D vs. U] interaction in Table 1; Fig. 4). In contrast, the biomass of the more recent pennates sank consistently during the whole experiment (significant D vs. U effect and non-significant Trap $\times[D$ vs. U] interaction in Table 1; Fig. 4).This pattern is not due to a lack of buoyancy regulation in pennate diatoms. There were large BNA shifts in the pennate diatoms Gyrosigma 


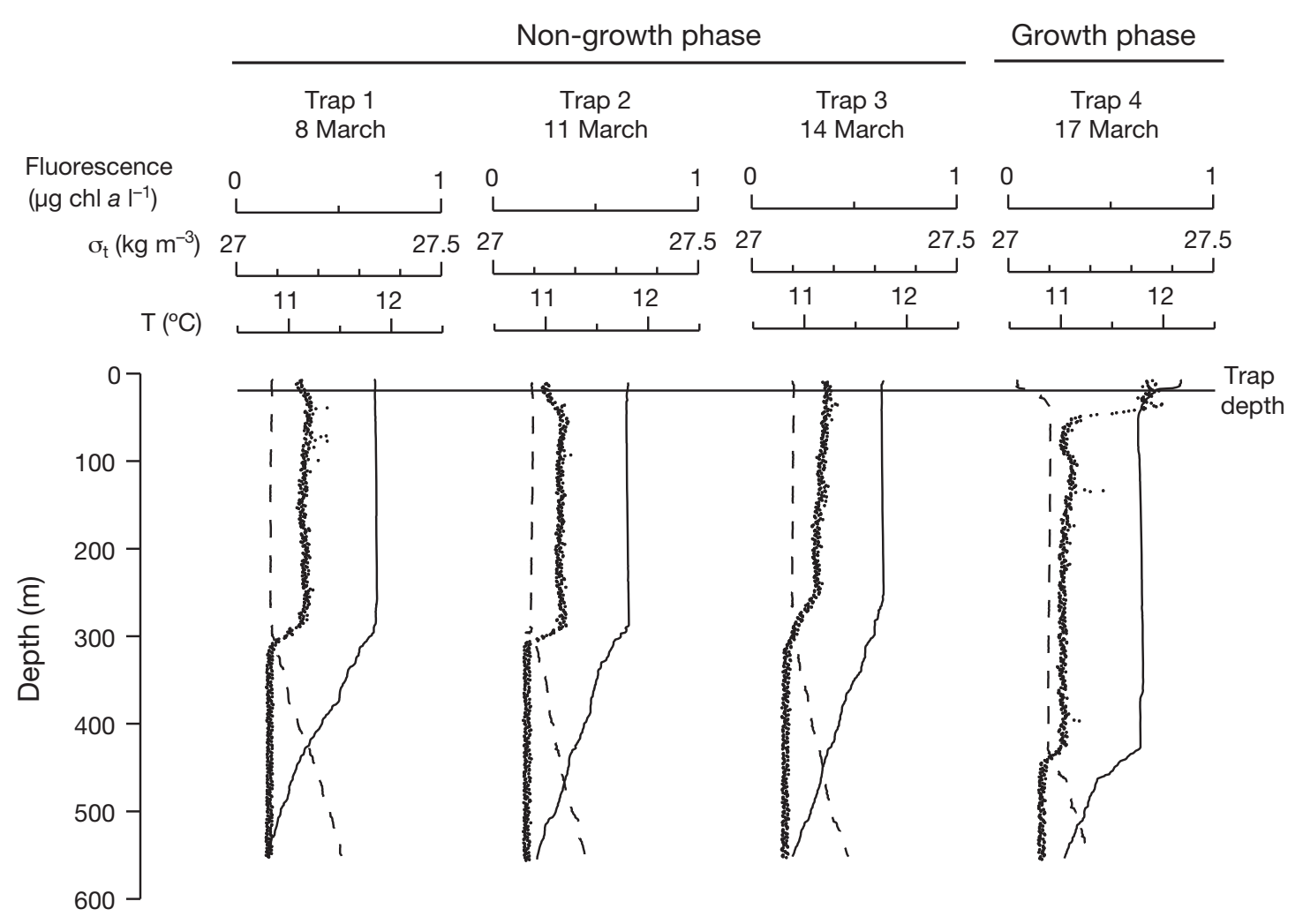

Fig. 3. CTD casts. Vertical profiles of temperature (solid lines), density (dashed lines) and fluorescence (dots). Casts were performed immediately after each of the 4 trap deployments. $\sigma_{t}$ : density; $T$ : temperature

spp. $\left(19.69 \pm 23.64\right.$ to $1.28 \pm 1.13 \mathrm{~m} \mathrm{~d}^{-1}$, mean $\left.\pm \mathrm{SD}\right)$, Nitzchia longissima $\left(3.32 \pm 5.23\right.$ to $\left.0.79 \pm 0.65 \mathrm{~m} \mathrm{~d}^{-1}\right)$ and Stauroneis spp. $\left(0.43 \pm 0.89\right.$ to $\left.-1.98 \pm 3.66 \mathrm{~m} \mathrm{~d}^{-1}\right)$ (Fig. 5). Cells of this last species showed the strongest positive buoyancy during the growth phase of the bloom (i.e. it had the lowest BNA; Fig. 5). However, buoyancy regulation in pennates seemed less efficient than that of the centrics, whose BNAs were usually less variable and closer to neutral buoyancy (Fig. 5). In general, sinking may have been enhanced by water turbulence in Traps 1 to 3 (Ruiz et al. 2004), but this does not explain positive buoyancy in Trap 4 .

We cannot be sure about the species that bloomed at our study site, because we did not collect samples for the analysis of phytoplankton composition in the water column, except for those belonging to the trap experiment. During our last trap deployment, chains of Chaetoceros spp. dominated the assemblage at $20 \mathrm{~m}$ depth, according to the phytoplankton composition in our control tubes. Moreover, project RADIALES (Valdés et al. 2007) sampled Stn CUD-2 (www. seriestemporales-ieo.net/muestreos/rad_Ast.htm), a station $135 \mathrm{~m}$ deep located some $100 \mathrm{~km}$ to the west of our experimental site $\left(43^{\circ} 42^{\prime} \mathrm{N}, 06^{\circ} 09^{\prime} \mathrm{W}\right)$, for phytoplankton on the same date. At Stn CUD-2, the centric diatom C. socialis dominated the assemblage numerically, followed by Thalassiosira angulata and T. rotula (R. Anadón pers. comm.). Thus dominance of Chaetoceros spp. $2 \mathrm{~d}$ prior to the peak of the SPB probably was a regional, rather than local, phenomenon. Among the centrics, diatoms of the genus Chaetoceros showed the strongest positive buoyancy in our experiment (Fig. 5), which is consistent with evidence that lower or negligible sinking rates of individual species in the pre-bloom phase are a predictor of individual species success during the following spring bloom (Waite et al. 1992b). Interestingly, the pennate Stauroneis spp. was absent from Stn CUD-2, although it showed the strongest positive buoyancy during our last trap deployment. Again, this could indicate an altogether different buoyancy behaviour in pennates.

In the laboratory, large diatoms exhibit more effective buoyancy control than smaller ones, probably due to a larger vacuolar and protoplasmic volume, allowing for more effective ion accumulation (Waite et al. 1997). Accordingly, in our experiment we should expect low sinking rates during the growth phase, and a trend of increasing sinking rate with cell volume during the non-growth phase, with a threshold for buoyancy shifts at a cell volume of $200 \mathrm{\mu m}^{3}$ (Waite et al. 1997). Unfortu- 


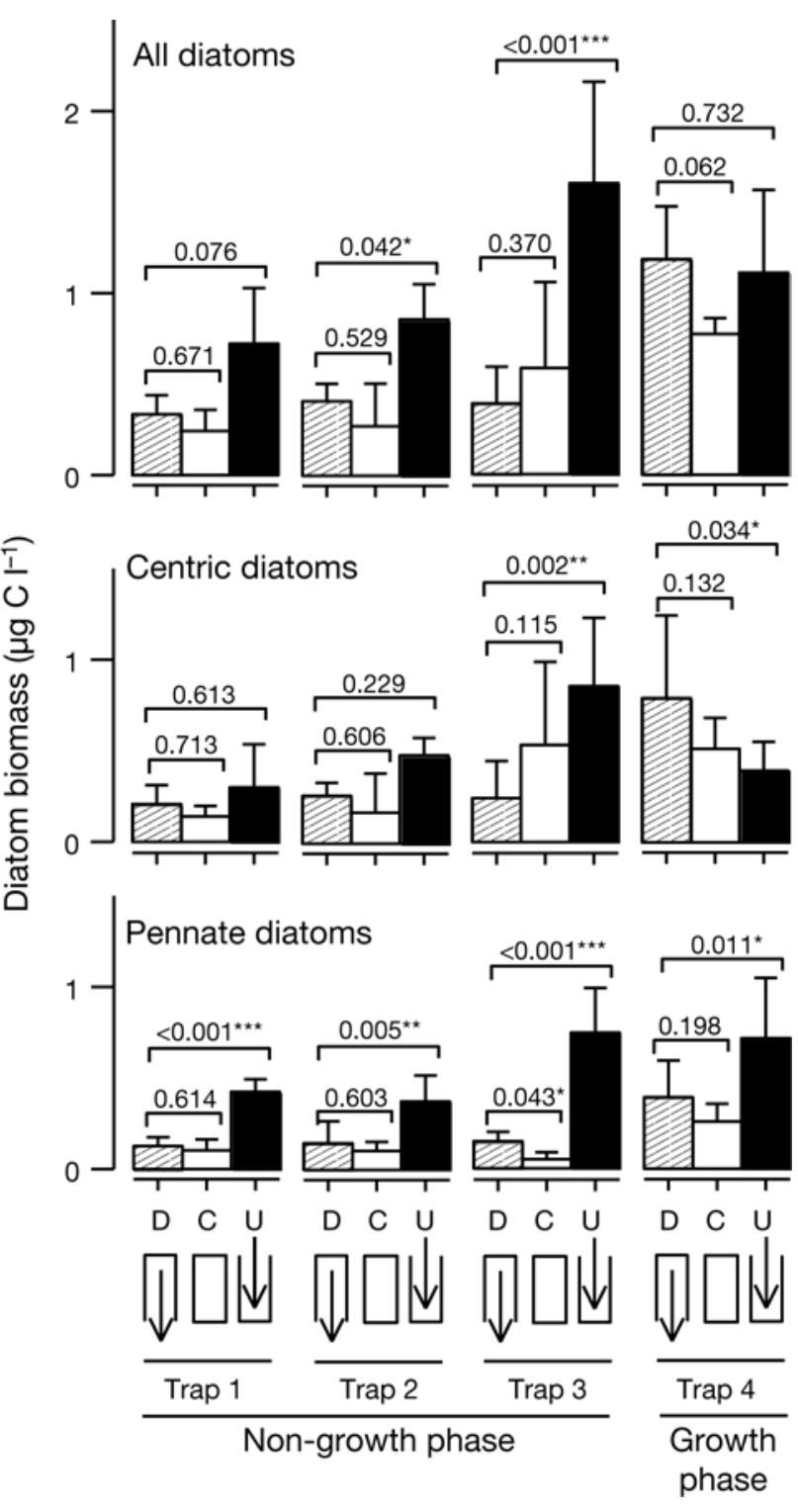

Fig. 4. Bulk diatom accumulation in the buoyancy traps. Mean $( \pm \mathrm{SD})$ carbon biomasses of total, centric and pennate diatoms for each of the combinations of collection tube (D: downwardfacing tubes; U: upward-facing tubes; C: control tubes) and trap (Traps 1 to 4 ) are given. Numbers indicate the significance of planned, D vs. U and D vs. C comparisons within each of the trap deployments (see 'Materials and methods';

Tables 2 to 4$) .{ }^{*} \mathrm{p}<0.05{ }^{* *} \mathrm{p}<0.01 ;{ }^{* * *} \mathrm{p}<0.001$

nately, our species-specific data are too scarce and variable to offer conclusive support for this hypothesis (Fig. 5). Certainly, the large pennates Gyrosigma spp. and Frustulia rhomboides sank rapidly during the nongrowth phase (Fig. 5), but the giant diatom Ditylum brightwellii was close to neutral buoyancy (Trap 4, Fig. 5). This suggests that a taxonomic differentiation between centrics and pennates overrides size effects on buoyancy regulation.
Comparison of particle accumulation between $\mathrm{D}$ and C tubes also indicates that the buoyancy shift is fast. During the sinking, non-growth phase, we expected $d<c$, because the D tubes should have lost diatoms through their lower openings (Fig. 1A). However, $d$ was not significantly smaller than $c$ in any of the traps for any of the diatom groups (with the exception of pennate diatoms during Trap 3; Fig. 4, Tables 2 to 4), while neither the D vs. C main effect nor the Trap $\times(D$ vs. C) interaction were significant (Table 1). It is plausible that entrapment within the calm environment of the transparent $\mathrm{D}$ tubes exposed the diatoms to continuous light, allowing growth and flotation early after deployment of the trap. Response times of only $3 \mathrm{~h}$ have been reported in the laboratory (Waite et al. 1992a); therefore, such a rapid buoyancy shift is not unlikely. Its timescale lies below the typical generation time of diatoms, thus it is a physiological acclimation response which sets the conditions for the subsequent population response.

The adaptive potential of opportunistic flotation in the context of the spring bloom is clear. Wind-gener-

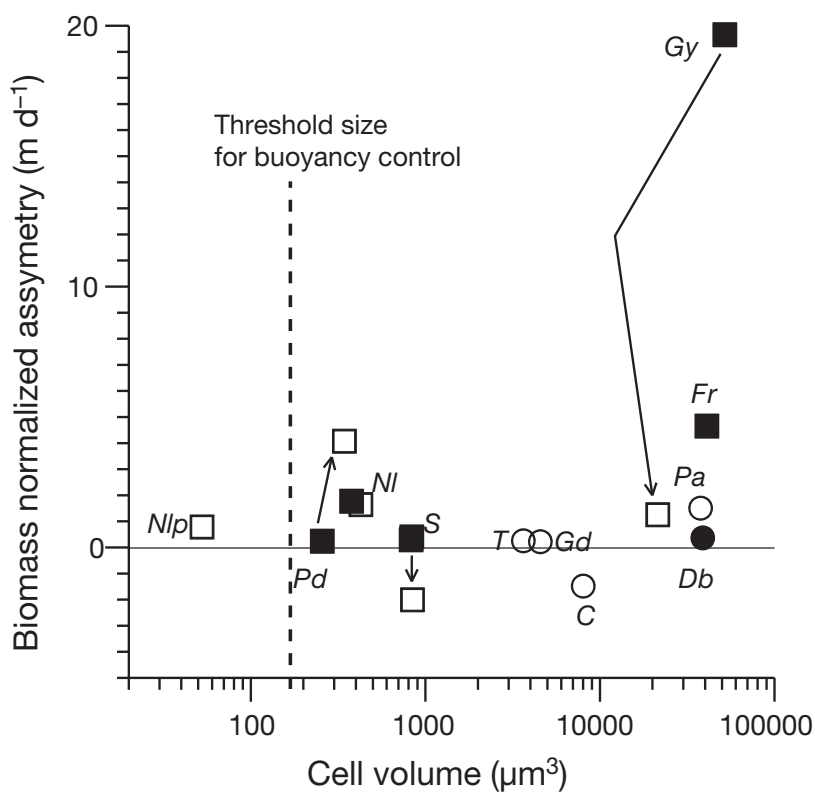

Fig. 5. Species-specific, biomass-normalized asymmetries (BNA) vs. mean cell size $( \pm \mathrm{SD})$. Positive values of BNA indicate the predominance of sinking, while negative values correspond to a net upward flux in a given species. Circles correspond to centric diatoms, squares to pennate diatoms. Filled symbols correspond to the non-growth phase (mean of Traps 1,2 and 3), while empty symbols correspond to the growth phase (Trap 4). C: Chaetoceros spp.; Db: Ditylum brightwellii; Fr: Frustulia rhomboides; Gd: Guinardia delicatula; Gy: Gyrosigma spp.; Nl: Nitzschia longissima; Nlp: Nitzschia longissima (small form); Pa: Proboscia alata; Pd: Pseudonitzschia delicatissima; S: Stauroneis spp.; T: Thalassiosira spp. The vertical, dashed line corresponds to the minimum volume for active sinking rate control as estimated by Waite et al. (1997) 
Table 1. Summary of the planned tests for the buoyancy trap experiment. D vs. U and D vs. C test for systematic differences in diatom accumulation across all 4 traps. F-values for Trap $\times(\mathrm{D}$ vs. U) and Trap $\times(\mathrm{D}$ vs. C) test for across-trap shifts in the asymmetry between D and U and between D and C tubes, respectively. See detailed ANOVA in Tables 2 (total diatoms), 3 (centric diatoms) and 4 (pennate diatoms). D: downward-facing tubes; U: upward-facing tubes; C: control tubes

\begin{tabular}{|c|c|c|c|c|c|c|c|c|}
\hline & \multicolumn{2}{|c|}{ D vs. U } & \multicolumn{2}{|c|}{ D vs. C } & \multicolumn{2}{|c|}{ Trap × (D vs. U $)$} & \multicolumn{2}{|c|}{ Trap × (D vs. C $)$} \\
\hline & $F_{1,6}$ & $\mathrm{p}$ & $F_{1,6}$ & $\mathrm{p}$ & $F_{3,36}$ & $\mathrm{p}$ & $F_{3,36}$ & $\mathrm{p}$ \\
\hline All diatoms & 6.81 & 0.040 & 0.35 & 0.578 & 6.22 & 0.002 & 1.35 & 0.274 \\
\hline Centric diatoms & 0.76 & 0.416 & 0.06 & 0.815 & 5.35 & 0.004 & 1.74 & 0.176 \\
\hline Pennate diatoms & 25.91 & 0.002 & 2.28 & 0.182 & 1.91 & 0.146 & 0.58 & 0.634 \\
\hline
\end{tabular}

Table 2. Full ANOVA for total diatoms. Source terms in italics indicate planned comparisons. Data were checked for normality (Kolmogorov-Smirnoff test) and homogeneity of variances (Cochran's test). Diatom concentrations in ng $\mathrm{C}^{-1}$ were used for the analysis. D: downward-facing tubes; U: upward-facing tubes; C: control tubes

\begin{tabular}{|c|c|c|c|c|c|c|}
\hline Source & $\begin{array}{c}\mathrm{df} \\
\text { effect }\end{array}$ & $\begin{array}{c}\text { MS } \\
\text { effect }\end{array}$ & $\begin{array}{c}\text { df } \\
\text { error }\end{array}$ & $\begin{array}{l}\text { MS } \\
\text { error }\end{array}$ & $F$ & $\mathrm{p}$ \\
\hline Trap & 3 & 938808 & 36 & 90981 & 10.319 & 0.001 \\
\hline Tube & 2 & 1662052 & 6 & 286796 & 5.795 & 0.040 \\
\hline$D$ Vs. $U$ & 1 & 1954504 & 6 & 286796 & 6.815 & 0.040 \\
\hline$D_{\text {vs. }} C$ & 1 & 98904 & 6 & 286796 & 0.345 & 0.578 \\
\hline Trap $\times$ Tube & 6 & 286796 & 36 & 90981 & 3.152 & 0.014 \\
\hline Trap $\times(D$ vs. $U)$ & 3 & 566163 & 36 & 90981 & 6.223 & 0.002 \\
\hline Trap $\times(D$ vs. $C)$ & 3 & 122782 & 36 & 90981 & 1.350 & 0.274 \\
\hline Error & 36 & 90981 & & & & \\
\hline$D$ vs. $U$ within Trap 1 & 1 & 303480 & 36 & 90981 & 3.336 & 0.076 \\
\hline$D$ vs. $U$ within Trap 2 & 1 & 405572 & 36 & 90981 & 4.458 & 0.042 \\
\hline$D$ vs. $U$ within Trap 3 & 1 & 2933065 & 36 & 90981 & 32.238 & 0.001 \\
\hline$D$ vs. $U$ within Trap 4 & 1 & 10875 & 36 & 90981 & 0.120 & 0.732 \\
\hline$D$ vs. $C$ within Trap 1 & 1 & 16651 & 36 & 90981 & 0.183 & 0.671 \\
\hline$D$ vs. $C$ within Trap 2 & 1 & 36847 & 36 & 90981 & 0.405 & 0.529 \\
\hline$D$ vs. $C$ within Trap 3 & 1 & 75066 & 36 & 90981 & 0.825 & 0.370 \\
\hline$D$ vs. $C$ within Trap 4 & 1 & 338688 & 36 & 90981 & 3.723 & 0.062 \\
\hline
\end{tabular}

Table 3. Full ANOVA for centric diatoms. Same formalities as in Table 2. D: downward-facing tubes; U: upward-facing tubes; C: control tubes

\begin{tabular}{|c|c|c|c|c|c|c|}
\hline Source & $\begin{array}{c}\mathrm{df} \\
\text { effect }\end{array}$ & $\begin{array}{c}\text { MS } \\
\text { effect }\end{array}$ & $\begin{array}{c}\text { df } \\
\text { error }\end{array}$ & $\begin{array}{l}\text { MS } \\
\text { error }\end{array}$ & $F$ & $\mathrm{p}$ \\
\hline Trap & 3 & 364754 & 36 & 65256 & 5.590 & 0.003 \\
\hline Tube & 2 & 126358 & 6 & 182959 & 0.691 & 0.537 \\
\hline$D$ vs. $U$ & 1 & 139575 & 6 & 182959 & 0.763 & 0.416 \\
\hline$D$ vs. $C$ & 1 & 10921 & 6 & 182959 & 0.060 & 0.815 \\
\hline Trap $\times$ Tube & 6 & 182959 & 36 & 65256 & 2.804 & 0.024 \\
\hline Trap $\times(D$ vs. $U)$ & 3 & 349364 & 36 & 65256 & 5.354 & 0.004 \\
\hline Trap $\times(D$ vs. $C)$ & 3 & 113690 & 36 & 65256 & 1.742 & 0.176 \\
\hline Error & 36 & 65256 & & & & \\
\hline$D$ vs. $U$ within Trap 1 & 1 & 16961 & 36 & 65256 & 0.260 & 0.613 \\
\hline$D$ vs. $U$ within Trap 2 & 1 & 97633 & 36 & 65256 & 1.496 & 0.229 \\
\hline$D$ vs. $U$ within Trap 3 & 1 & 754703 & 36 & 65256 & 11.565 & 0.002 \\
\hline$D$ vs. $U$ within Trap 4 & 1 & 318370 & 36 & 65256 & 4.879 & 0.034 \\
\hline$D$ vs. $C$ within Trap 1 & 1 & 8981 & 36 & 65256 & 0.138 & 0.713 \\
\hline$D$ vs. $C$ within Trap 2 & 1 & 17645 & 36 & 65256 & 0.270 & 0.606 \\
\hline$D$ vs. $C$ within Trap 3 & 1 & 170183 & 36 & 65256 & 2.608 & 0.115 \\
\hline$D$ vs. $C$ within Trap 4 & 1 & 155183 & 36 & 65256 & 2.378 & 0.132 \\
\hline
\end{tabular}


Table 4. Full ANOVA for pennate diatoms. Same formalities as in Table 2. Data were square root $(x+1)$-transformed to homogenize variances. D: downward-facing tubes; U: upward-facing tubes; C: control tubes

\begin{tabular}{|c|c|c|c|c|c|c|}
\hline Source & $\begin{array}{c}\mathrm{df} \\
\text { effect }\end{array}$ & $\begin{array}{c}\text { MS } \\
\text { effect }\end{array}$ & $\begin{array}{c}\text { df } \\
\text { error }\end{array}$ & $\begin{array}{c}\text { MS } \\
\text { error }\end{array}$ & $F$ & $\mathrm{p}$ \\
\hline Trap & 3 & 125 & 36 & 14 & 9.164 & 0.001 \\
\hline Tube & 2 & 708 & 6 & 30 & 23.908 & 0.001 \\
\hline$D$ vs. $U$ & 1 & 767 & 6 & 30 & 25.907 & 0.002 \\
\hline$D$ vs. $C$ & 1 & 67 & 6 & 30 & 2.276 & 0.182 \\
\hline Trap $\times$ Tube & 6 & 30 & 36 & 14 & 2.172 & 0.069 \\
\hline Trap $\times(D$ vs. $U)$ & 3 & 26 & 36 & 14 & 1.908 & 0.146 \\
\hline Trap $\times(D$ vs. $C)$ & 3 & 8 & 36 & 14 & 0.577 & 0.634 \\
\hline Error & 36 & 14 & & & & \\
\hline$D$ vs. $U$ within Trap 1 & 1 & 177 & 36 & 14 & 12.959 & 0.001 \\
\hline$D$ vs. $U$ within Trap 2 & 1 & 120 & 36 & 14 & 8.800 & 0.005 \\
\hline$D$ vs. $U$ within Trap 3 & 1 & 450 & 36 & 14 & 32.975 & 0.001 \\
\hline$D$ vs. $U$ within Trap 4 & 1 & 99 & 36 & 14 & 7.250 & 0.011 \\
\hline$D$ vs. $C$ within Trap 1 & 1 & 4 & 36 & 14 & 0.258 & 0.614 \\
\hline$D$ vs. $C$ within Trap 2 & 1 & 4 & 36 & 14 & 0.275 & 0.603 \\
\hline$D$ vs. $C$ within Trap 3 & 1 & 60 & 36 & 14 & 4.423 & 0.043 \\
\hline$D$ vs. $C$ within Trap 4 & 1 & 23 & 36 & 14 & 1.717 & 0.198 \\
\hline
\end{tabular}

ated turbulence keeps winter diatom populations mixed within a layer hundreds of meters deep. As a consequence, diatoms spend a substantial fraction of their time in dark portions of the water column, where they respire but do not photosynthesize, thus their growth is limited by light (Sverdrup 1953). In these conditions, any ion pump would not function, since these pumps necessarily require an energy input, and the diatoms would sink, which was readily apparent during the non-growth phase in our experiment. The onset of the SPB occurs when diatoms are constrained to the few upper meters of the water column by reductions of either the depth of the mixing layer (Sverdrup 1953, Platt et al. 1991), the turbulence levels (Sverdrup 1953, Huisman et al. 1999) or the velocity of convective mixing (Backhaus et al. 2003, D'Asaro 2008). These mechanisms release the cells from light limitation, powering the ion pump and allowing the diatoms to float and remain in the upper illuminated layer of the ocean, extracting the most benefit from a transient favourable situation. The phenomenon is elusive due to its facultative nature, but the present study demonstrates that its detection in situ is logistically and methodologically possible. Neutral, or even positive, diatom buoyancy during the development phase of the SPB will shift model predictions of initial conditions towards deeper mixed layers, stronger winds or faster ocean convection, which in turn involves earlier, more frequent and more intense blooms. Neutral buoyancy also leaves grazing as the only loss term, which implies that the discrepancy between model predictions without loss terms and bloom observations can be used to estimate grazing activity, either locally or synoptically, if satellite observations are used to time the blooms (see Siegel et al. 2002 for a similar exercise).

Because of their emphasis on the measurement of downward fluxes of biogeochemically important elements, sediment traps invariably incorporate upwardfacing collectors only (e.g. Riebesell 1989; for a remarkable exception, see Simoneit et al. 1986), rarely incorporate control collectors, measurements frequently remain unreplicated and traps are commonly placed below the upper mixed layer of the ocean to avoid the confounding effect of turbulence (Buesseler et al. 2007). From a phytoplankton ecologist's point of view, this is far from where the action is. Our experiment represents a preliminary demonstration of a different approach to sediment trapping that can be refined in multiple ways. However, the fact that it allows rejection of the null, fixed sinking hypothesis indicates that the design was adequate and the buoyancy shift was large. It confirms in situ and during the SPB an idea that was already well grounded on laboratory studies and in a few field observations: that diatoms respond to environmental shifts with abrupt and rapid changes in their buoyancy properties, a fact that seems to pass unnoticed in modelling and theoretical studies. Indeed, turbulence brings nutrients and diatoms to the surface, where they become exposed to light, just like a plough turns up deeply buried nutrients and seeds to the surface of the earth. However, the existence of a buoyancy control mechanism implies that, once near the surface, diatoms will not require a minimum level of turbulence to remain in the euphotic layer, as implied in the theoretical analysis by Huisman \& Sommeijer (2002). Instead, diatoms should float for as long 
as there are nutrients and light to sustain growth, as observed in microcosm experiments by Richardson \& Cullen (1995). There is now sufficient evidence to confirm Hutchinson's (1967) early insight on the prevalence of strong selection pressures against sinking phytoplankton. Diatoms, the paradigm of sinking phytoplankton, manage to persist by floating opportunistically.

Acknowledgements. We thank the Captain and crew onboard the RV 'García del Cid' for their courageous support during the cruise, particularly during deployment and tracking of the buoyancy traps under harsh weather conditions. We also thank Santos and Silvino S. A. and TRANSGLASS S. L. for their contribution to trap design, Puertos del Estado (Ministerio de Fomento) for providing wind data, J. Arrontes for statistical advice, C. Pedrós-Alió and V. Smetacek for their critical reading and 3 anonymous referees for comments that greatly improved the paper. This research was funded by the Spanish Ministry of Education and Science, under project DINAPROFIT (Dynamics of Winter Phytoplankton Blooms; CTM2006-05588/MAR). F.G.T. was supported through a FICYT grant (Principado de Asturias). J.L.A. dedicates this paper to the memory of his parents, J. L. Acuña-Bascones and M. L. Fernández-Peral.

\section{LITERATURE CITED}

Anderson L, Sweeney B (1977) Diel changes in the sedimentation characteristics of Ditylum brightwellii, a marine centric diatom: changes in cellular lipids and effects of respiratory inhibitors and ion-transport modifiers. Limnol Oceanogr 22:539-552

Backhaus JO, Hegseth EN, Wehde H, Irigoien X, Hatten K, Logemann K (2003) Convection and primary production in winter. Mar Ecol Prog Ser 251:1-14

Boyd CM, Gradmann D (2002) Impact of osmolytes on buoyancy of marine phytoplankton. Mar Biol 141:605-618

Buesseler KO, Antia AN, Chen M, Fowler SW and others (2007) An assessment of the use of sediment traps for estimating upper ocean particle fluxes. J Mar Res 65: 345-416

D'Asaro EA (2008) Convection and the seeding of the North Atlantic Bloom. J Mar Syst 69:233-237

Ellertsen HC (1993) Spring blooms and stratification. Nature 363:24

Falkowski PG, Barber RT, Smetaceck V (1998) Biogeochemical controls and feedbacks on ocean primary production. Science 281:200-206

Feldman GC, McClain CR (2008) Ocean Color Web. In: Kuring N, Bailey SW (eds) MODIS Reprocessing 1.1 and SeaWiFS Reprocessing 5. NASA Goddard Space Flight Center. Available at http://oceancolor.gsfc.nasa.gov/

Hillebrand H, Dürselen C, Kirschtel D, Pollingher U, Zohary T (1999) Biovolume calculation for pelagic and benthic microalgae. J Phycol 35:403-424

Huisman J, Sommeijer B (2002) Maximal sustainable sinking velocity of phytoplankton. Mar Ecol Prog Ser 244:39-48

Huisman J, Oostveen Pv, Weissing FJ (1999) Critical depth and critical turbulence: two different mechanisms for the development of phytoplankton blooms. Limnol Oceanogr 44:1781-1787

Huisman J, Arrayás M, Ebert U, Sommeijer B (2002) How do sinking phytoplankton species manage to persist? Am Nat 159:245-254

Hutchinson GE (1967) A treatise on limnology. II. Introduction to lake biology and the limnoplankton. Wiley, New York

Jitts HR, Morel A, Saijo Y (1976) The relation of oceanic primary production to available photosynthetic irradiance. Aust J Mar Freshw Res 27:441-454

Lännergren C (1979) Buoyancy of natural populations of marine phytoplankton. Mar Biol 54:1-10

McKone MJ (1993) Statistical analysis of experiments conducted at multiple sites. Oikos 67:184-186

Menden-Deuer S, Lessard E (2000) Carbon to volume relationship for dinoflagellates, diatoms, and other protist plankton. Limnol Oceanogr 45:569-579

Miller CB (2004) Biological oceanography. Blackwell Science, Oxford

Platt T, Bird DF, Sathyendranath S (1991) Critical depth and marine primary productivity. Proc Biol Sci 246:205-217

Raven JA, Waite AM (2004) The evolution of silicification in diatoms: inescapable sinking and sinking as escape? New Phytol 162:45-61

Richardson TL, Cullen JJ (1995) Changes in buoyancy and chemical composition during growth of a coastal marine diatom: ecological and biogeochemical consequences. Mar Ecol Prog Ser 128:77-90

Riebesell U (1989) Comparison of sinking and sedimentation rate measurements in a diatom winter/spring bloom. Mar Ecol Prog Ser 54:109-119

Riley GA, Stommel H, Bumpus DF (1949) Quantitative ecology of the plankton of the western North Atlantic. Bull Bingham Oceanogr Coll 12:1-169

- Ruiz J, Macias D, Peters F (2004) Turbulence increases the average settling velocity of phytoplankton cells. Proc Natl Acad Sci USA 101:17720-17724

Shigesada N, Okubo A (1981) Analysis of the self shading effect on algal vertical distribution in natural waters. J Math Biol 12:311-326

Siegel DA, Doney SC, Yoder JA (2002) The North Atlantic spring phytoplankton bloom and Sverdrup's critical depth hypothesis. Science 296:730-733

Simoneit BRT, Grimalt JO, Fischer K, Dymond J (1986) Upward and downward flux of particulate organic material in abyssal waters of the Pacific Ocean. Naturwissenschaften 73:322-325

Smayda TJ (1970) The suspension and sinking of phytoplankton in the sea. Oceanogr Mar Biol Annu Rev 8:353-414

Smetacek VS (1985) Role of sinking in diatom life-history cycles: ecological, evolutionary and geological significance. Mar Biol 84:239-251

Somavilla R, González-Pola C, Rodriguez C, Josey S, Sanchez $\mathrm{RF}$, Lavin A (2009) Large changes in the hydrographic structure of the Bay of Biscay after the extreme mixing of winter 2005. J Geophys Res 114:C01001, doi:10.1029/ 2008JC004974

Sverdrup HU (1953) On conditions for the vernal blooming of phytoplankton. J Cons Int Explor Mer 18:287-295

> Townsend DW, Keller MD, Sieracki ME, Ackleson SG (1992) Spring phytoplankton blooms in the absence of vertical water column stratification. Nature 360:59-62

Underwood AJ (1997) Experiments in ecology. Cambridge University Press, Cambridge

Valdés L, López-Urrutia A, Cabal J, Alvarez-Ossorio M and others (2007) A decade of sampling in the Bay of Biscay: What are the zooplankton time series telling us? Prog Oceanogr 74:98-114

> Villareal TA, Altabet MA, Culver-Rymsza K (1993) Nitrogen transport by vertically migrating diatoms mats in the 
North Pacific Ocean. Nature 363:709-712

> Villareal TA, Pilskaln C, Brzezinski M, Lipschultz F, Dennett M, Gardner GB (1999) Upward transport of oceanic nitrate by migrating diatom mats. Nature 397:423-425

Waite A, Harrison PJ (1992) Role of sinking and ascent during sexual reproduction in the diatom Ditylum brightwellii. Mar Ecol Prog Ser 87:113-122

Waite AM, Nodder SD (2001) The effect of in situ iron addition on the sinking rates and export flux of Southern Ocean diatoms. Deep-Sea Res II 48:2635-2654

Waite AM, Thompson PA, Harrison PJ (1992a) Does energy control the sinking rates of marine diatoms? Limnol Oceanogr 37:468-477

Editorial responsibility: Peter Verity,

Savannah, Georgia, USA
Waite AM, Bienfang PK, Harrison PJ (1992b) Spring bloom sedimentation in a subarctic ecosystem. II. Succession and sedimentation. Mar Biol 114:131-138

> Waite A, Fisher A, Thompson PA, Harrison PJ (1997) Sinking rate versus cell volume relationships illuminate sinking rate control mechanisms in marine diatoms. Mar Ecol Prog Ser 157:97-108

Woods S, Villareal TA (2008) Intracellular ion concentrations and cell sap density in positively buoyant oceanic phytoplankton. Nova Hedwigia Beih 133:131-145

Yentsch CS, Menzel DW (1963) A method for the determination of phytoplankton chlorophyll and phaeophytin by fluorescence. Deep-Sea Res 10:221-231

Submitted: July 30, 2009; Accepted: November 5, 2009 Proofs received from author(s): February 5, 2010 